\title{
Identification of the TMV Replicase Sequence That Activates the $N$ Gene-Mediated Hypersensitive Response
}

\author{
Hal S. Padgett, ${ }^{1}$ Yuichiro Watanabe, ${ }^{2}$ and Roger N. Beachy ${ }^{1}$ \\ ${ }^{1}$ Division of Plant Biology, The Scripps Research Institute, BCC 206, La Jolla, CA 92037, U.S.A.; \\ ${ }^{2}$ Department of Life Sciences, Graduate School of Arts and Sciences, University of Tokyo, Meguro-ku, \\ Tokyo 153, Japan \\ Received 8 April 1997. Accepted 19 May 1997.
}

\begin{abstract}
The $N$ gene-mediated hypersensitive response (HR) in tobacco provides a high degree of resistance against most tobamoviruses by halting the progress of infection at the site of inoculation. A previous report indicated a role for the 126/183-kDa replicase in induction of the HR in tobacco containing the $N$ gene $(H$. S. Padgett and R. N. Beachy, Plant Cell 5:577-586, 1993). Chimeric virus genomes were constructed in which the genes encoding the 126/183-kDa proteins of the HR-eliciting pathogen, tobacco mosaic virus (TMV), and the resistance breaking tobamovirus, $\mathrm{Ob}$, were exchanged. Inoculation of the chimeric viruses to leaves of Nicotiana tabacum cv. Xanthi NN confirmed that either the replicase protein of TMV or its mRNA was responsible for induction of HR. An expression vector based on the $\mathrm{Ob}$ virus was used to express fragments of various replicase genes. With this approach, it was determined that the HR is caused by a portion of the replicase protein extending from amino acid 692 to 1116. Consistent with this result, $\mathrm{Ob}$ mutants that induce the HR on NN tobacco were found to carry mutations within the same portion of the replicase gene. The $N$ genemediated HR is inactive at high temperatures, yet these mutants were able to overcome the HR at significantly lower temperatures than could TMV, indicating that the temperature sensitivity of the $N$ gene response is manifested at the level of interaction between the virus and the defense response mechanism.
\end{abstract}

Infection by a plant pathogen frequently results in a hypersensitive response (HR), an active form of defense that is characterized by the appearance of necrosis at the site of infection and inhibition of further pathogen multiplication and spread (Keen 1992). The HR is highly pathogen-specific and likely involves interaction between the product(s) of a plant disease resistance gene and the product of a corresponding pathogen gene, generally referred to as an avirulence gene (Keen 1990).

Tobacco (Nicotiana tabacum) lines that harbor the $N$ gene react hypersensitively to infection by tobacco mosaic virus

Corresponding author: Roger N. Beachy; Phone: (619) 784-2917; Fax: (619) 784-2994; E-mail: beachy@ scripps.edu
(TMV) and to most other tobamoviruses with the exception of the tobamovirus $\mathrm{Ob}$, which can systemically infect these plants (Tobias et al. 1982; Csillery et al. 1983). The sequence of the $N$ gene predicts a protein with significant homology to a number of other known plant disease resistance genes (Whitham et al. 1994; Jones 1996). Similarities of the N protein to sequences in the interleukin-1 receptor and the Drosophila Toll protein suggest that it may function as a receptor for the signal from the virus that activates HR. At present, however, there is no evidence of direct physical interaction between the $\mathrm{N}$ protein and its putative viral ligand. The $N$ gene response is temperature sensitive (Samuel 1931) and protein phosphorylation is likely to play a role in its signaling pathway (Dunigan and Madlener 1995). However, little else is known about the molecular and biochemical mechanisms that mediate pathogen recognition and induction of the $\mathrm{HR}$ in the $N$ gene system.

It has been shown that neither the movement protein (MP) nor the coat protein $(\mathrm{CP})$ of TMV is responsible for induction of the $N$ gene-mediated HR (Culver et al. 1991; Deom et al. 1991). We previously identified a mutant of $\mathrm{Ob}$ that causes HR in tobacco plants that carry the $N$ gene. Analysis of the mutant indicated that an altered replicase gene or its 126/183kDa protein products activated the $N$ gene response (Padgett and Beachy 1993). Here we report evidence that a portion of the replicase protein is required for induction of the $N$ genemediated HR, and demonstrate that the thermosensitivity of the response reflects a temperature sensitive interaction between the virus and its host.

\section{RESULTS}

The viral replicase is required for $H R$ induction.

In prior studies from this laboratory, analysis of a mutant of Ob implicated the replicase gene or its protein product in activation of the $N$ gene-mediated HR (Padgett and Beachy 1993). We subsequently undertook a more direct approach to define the role of replicase in induction of the HR by exchanging replicase gene sequences between the HR-eliciting virus, TMV, and the non-eliciting virus, $\mathrm{Ob}$. As diagrammed in Figure 1, each hybrid virus genome contained the $5^{\prime}$ untranslated region (UTR) and replicase gene of one virus joined to sequences encoding the MP, CP, and 3' UTR of the other 
virus. The construct containing the TMV replicase gene was named pT/O-MC3', while its counterpart, pO/T-MC3', encoded the $\mathrm{Ob}$ replicase. Viruses derived from in vitro transcribed RNA are designated by the name of the clone without " $p$ " as the prefix. Transcripts of both pT/O-MC3' and pO/TMC3' were inoculated onto the nonnecrotic tobacco host, Xanthi nn, and caused systemic infection (not shown), indicating that viral functions required for replication, local spread, and systemic invasion were maintained. On Xanthi NN plants, T/O-MC3' elicited necrotic local lesions while O/T-MC3' spread systemically without causing HR (Fig. 1). From these results, we concluded that induction of the $N$ gene-mediated HR is dependent upon either the TMV replicase gene sequence or the replicase protein.

\section{Induction of $\mathrm{HR}$ requires a portion of the replicase protein.}

To resolve the question of whether replicase RNA or protein activates the HR, and to more closely define the responsible sequences, we employed a system in which portions of the TMV replicase gene were inserted into an Ob-based viral expression vector. pOb $\Delta \mathrm{M}-\mathrm{Sac \textrm {I }}$ is a derivative of the plasmid pOb, from which the first 238 nucleotides (nt) of the $M P$ gene were deleted and replaced with a $S a c$ I site immediately adjacent to a downstream PstI site (Fig. 2A). In cells infected with transcripts from these plasmids, genes inserted in place of the $M P$ gene are expressed from the subgenomic RNA promoter that normally controls production of MP mRNA. Differences in gene length or AUG context may lead to differences in levels of gene expression. Although the resultant viruses are capable of replication, they cannot spread locally except in transgenic plants that contain $\mathrm{MP}[\mathrm{MP}(+)$ plants].

To determine whether the RNA sequences alone could elicit $\mathrm{HR}$, the chimeric clone pO/T-R2 was constructed (Fig. 2A). This clone contained nucleotides 259 to 4919 of the TMV replicase gene in the polycloning site of $\mathrm{pOb} \Delta \mathrm{M}-\mathrm{SacI}$, but the first ATG in this sequence was positioned out-of-phase with regard to the reading frame of the replicase. Upon translation, the RNA derived from this sequence is predicted to encode only a short peptide with a different reading frame. The other clones, pO/T-R3, pO/T-R6, and pO/T-R7, (Fig. 2) were constructed to produce portions of the TMV replicase protein beginning at amino acid 541, 1088, or 1143, respectively, and extending to amino acid 1616. The amber codon (amino acid 1117) that serves as the terminator for the $126-\mathrm{kDa}$ protein is

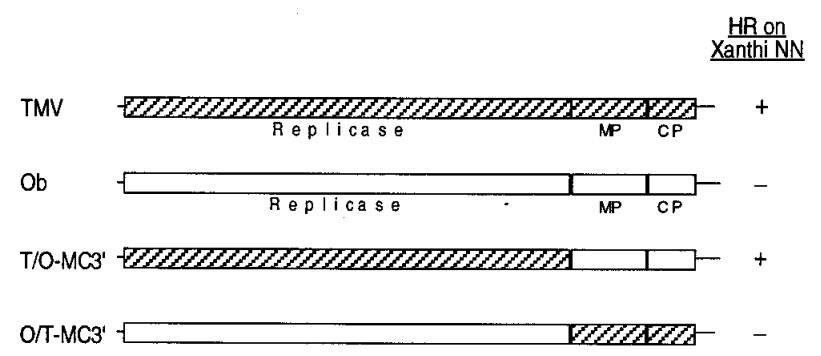

Fig. 1. The tobacco mosaic virus (TMV) $126-\mathrm{kDa}$ replicase gene is required for induction of the $N$ gene-mediated hypersensitive response. The genomes of TMV and $\mathrm{Ob}$ as well as the chimeras in which the $126 / 183-\mathrm{kDa}$ genes were exchanged are presented diagrammatically. The results of inoculation to leaves of Nicotinana tabacum cv. Xanthi NN plants are shown on the right. (+), induction of HR; (-), no HR. at nucleotide 3417 ; readthrough of this codon leads to the production of the $183-\mathrm{kDa}$ protein molecule during virus infection (Goelet et al. 1982). Transcripts from two independent clones of each construct, as well as from the vector, pOb $\Delta \mathrm{M}$ SacI, were inoculated to leaves of plant line 2005, a transgenic MP(+) line of Xanthi NN (Deom et al. 1991).

Leaves were scored for the presence or absence of necrotic local lesions. The results are shown in the column on the right of Figure 2A. As is the case with Ob on wild-type Xanthi NN

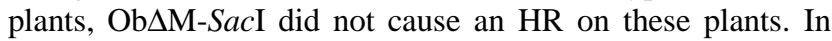
contrast, local lesions were observed on plants inoculated with transcripts from $\mathrm{pO} / \mathrm{T}-\mathrm{R} 3$, but not on plants challenged with transcripts from pO/T-R2, pO/T-R6, or pO/T-R7. The necrotic

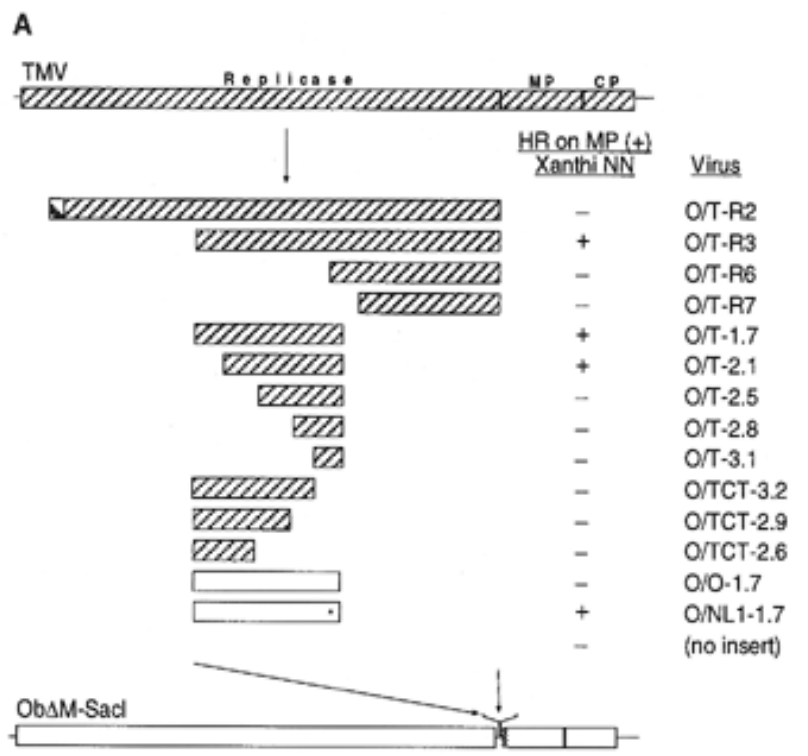

B

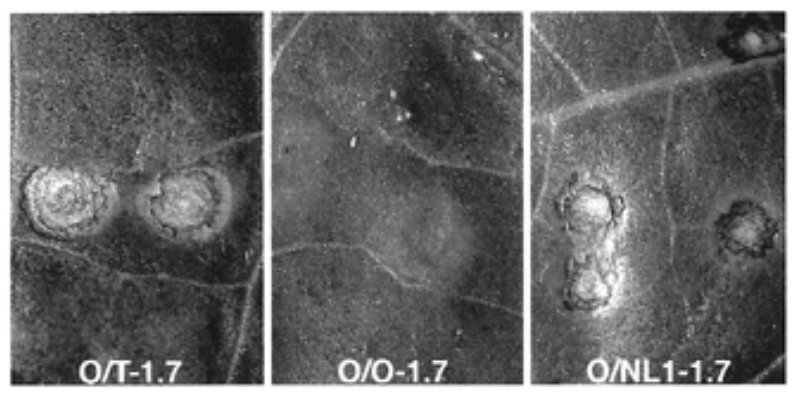

Fig. 2. Transient expression of $126 / 183-\mathrm{kDa}$ gene fragments in Ob. A, Portions of the $126 / 183-\mathrm{kDa}$ tobacco mosaic virus (TMV) replicase gene, as well as the $\mathrm{Ob}$ and ObNL-1.1 replicase genes, represented by boxes to the left of each virus name, were inserted into pOb $\Delta \mathrm{M}-\mathrm{SacI}$. The results of inoculation of the constructs onto leaves of the 2005 line of transgenic Xanthi NN that accumulates the movement protein of TMV are shown. (+), induction of the hypersensitive response (HR); (-) chlorotic spots on the inoculated leaf, with no HR. B, Photographs of leaves of line 2005 plants that were inoculated with either O/T-1.7, O/O1.7, or O/NL1-1.7. Fragments of the 126/183-kDa replicase gene that were used to construct $\mathrm{O} / \mathrm{T}-1.7$ and $\mathrm{O} / \mathrm{NL} 1-1.7$ were derived from the necrosis-inducing viruses TMV and ObNL-1.1, respectively, and activated the $\mathrm{HR}$. In contrast, $\mathrm{O} / \mathrm{O}-1.7$, the virus with the homologous fragment derived from $\mathrm{Ob}$, caused mild chlorosis with no HR. 
lesions induced by O/T-R3 were similar in appearance to local lesions caused by TMV, except that they were first observed at 3 days postinoculation (dpi) versus 2 dpi for TMV. On leaves inoculated with constructs that did not elicit HR, chlorotic areas served as evidence of infection. To confirm that induction of the HR on 2005 plants was dependent upon the presence of the $N$ gene, transcripts of pO/T-R3 were then inoculated to plant line 277, an $\mathrm{MP}(+)$ transgenic line of Xanthi nn tobacco (Deom et al. 1987). No HR was observed on these plants. The results of these experiments demonstrated that the 126/183$\mathrm{kDa}$ protein or a portion thereof, but not RNA, is necessary for activation of the $N$ gene-mediated HR.

Neither O/T-R6 nor O/T-R7 induced the HR on plant line 2005 , indicating that protein sequences encoded downstream of the amber termination codon (nucleotide 3417) had no inherent elicitor activity. However, since a significant portion of the TMV replicase encoded by pO/T-R3 should result from readthrough of the amber codon (Pelham 1978), the possibility remained that this region could affect HR induction through interaction with upstream portions of the polypeptide. Therefore, a clone was constructed that was analogous to pO/T-R3, except that the amber readthrough codon was converted to a stop codon (UAA), and sequences downstream of that codon were deleted. This construct would encode amino acids 541 to 1116 of the TMV 126-kDa protein. Transcripts derived from this clone, pO/T-1.7 (Fig. 2A), elicited HR on line 2005, showing that amino acid sequences downstream of replicase amino acid 1116 are not required for activation of HR.

To further characterize the boundaries of the elicitor, additional clones were generated in which the TMV protein encoded by $\mathrm{pO} / \mathrm{T}-1.7$ was shortened in increments of approximately 100 amino acids from either end. The series of $5^{\prime}$ truncations consisted of $\mathrm{pO} / \mathrm{T}-2.1, \mathrm{pO} / \mathrm{T}-2.5, \mathrm{pO} / \mathrm{T}-2.8$, and $\mathrm{pO} / \mathrm{T}-3.1$, each encoding a fragment of the TMV replicase beginning at amino acid number $692,806,910$, or 999, respectively, and terminating at amino acid 1116. In constructing the $5^{\prime}$ truncations, each polymerase chain reaction (PCR) primer was designed to span an in-frame ATG in the coding sequence, such that it would serve as the translation initiation site. With the exception of $\mathrm{pO} / \mathrm{T}-2.5$, the $4 \mathrm{nt}$ immediately preceding the ATG codons were changed to TAGG to provide a context for the translation start site that is similar to the context of the $M P$ gene (the $M P$ gene is expressed from this promoter in the wild-type virus). The $3^{\prime}$ truncations included pO/TCT-3.2, pO/TCT-2.9, and pO/TCT-2.6 (Fig. 2A); each began at amino acid 541 and was truncated at amino acid 1059,941 , or 837 , respectively.

Transcripts from three separate clones of each of the truncated constructs were inoculated to plant line 2005. As shown in Figure 2A, O/T-2.1 induced necrosis, whereas O/T-2.5, O/T-2.8, O/T-3.1, O/TCT-3.2, O/TCT-2.9, and O/TCT-2.6 did not. Based upon these studies, we propose that the polypeptide that extends from amino acid 692 to 1116 of the TMV replicase protein encodes a determinant that is required for induction of the $N$ gene-mediated HR.

ObNL-1, a mutant of Ob that induces HR on Xanthi NN, differs from $\mathrm{Ob}$ by a predicted change of proline to leucine at amino acid 1089 of the replicase protein. To determine whether or not the replicases from Ob and ObNL-1 would result in virulence and avirulence, respectively, when expressed as partial sequences, two additional clones, pO/O-1.7 and
pO/NL1-1.7, were constructed and tested. These clones are analogous to pO/T-1.7 (see Figure 2A), but encode fragments of replicase derived from $\mathrm{pOb}$ and pObNL-1, respectively, rather than from TMV.

The results of inoculating transcripts from these plasmids to leaves of plant line 2005 are shown in Figure 2A and 2B. O/O-1.7 did not elicit HR, whereas O/NL1-1.7 induced the formation of necrotic local lesions that were similar to lesions caused by $\mathrm{O} / \mathrm{T}-1.7$. These results demonstrated that the single amino acid change in the replicase of $\mathrm{Ob}$ that causes the necrotic phenotype of ObNL-1 can also activate the HR when a fragment of the viral replicase is expressed.

\section{Selection and analysis of additional ObNL mutants.}

To gain further insight into the nature of the polypeptide that induces the HR in the $N$ gene system, additional mutants of $\mathrm{Ob}$ that cause HR were isolated and characterized. The protocol for chemical mutagenesis of pOb that was described previously (Padgett and Beachy 1993) was used to select two mutants that elicit the HR, ObNL-2 and ObNL-3. Individual DNA segments spanning most of the genome of the wild-type virus were replaced with DNA fragments derived by PCR from each of the mutants (described in Materials and Methods) followed by transcription of the resulting sets of pOb/ObNL-2 and pOb/ObNL-3 plasmids and inoculation of transcripts to leaves of Xanthi NN plants. The infected plants were scored either for induction of HR or for systemic infection and absence of HR.

The mutations responsible for induction of the HR in both ObNL-2 and ObNL-3 were mapped to fragments containing nucleotides 3255 to 4081 . DNA sequence analysis of this region revealed that each mutant virus contained a change of a single amino acid in the $126-\mathrm{kDa}$ protein. ObNL-2 contains a $\mathrm{G}$ to A transition at nucleotide 3273 , with a predicted valine to isoleucine change at amino acid 1069 of the replicase. ObNL3 sustained a silent $\mathrm{T}$ to $\mathrm{C}$ change at nucleotide 3305 and a $\mathrm{C}$ to $\mathrm{T}$ transition at nucleotide 3333 that led to a predicted change of proline to serine at amino acid 1089 (Fig. 3). The

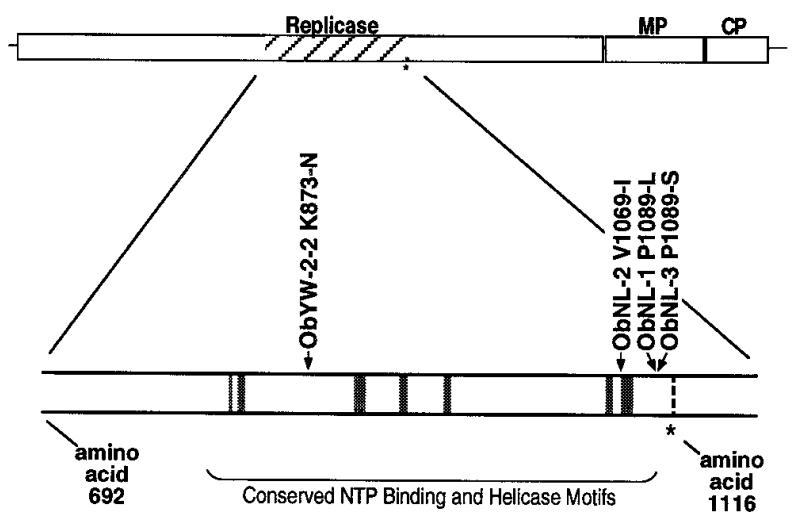

Fig. 3. Mutations in the $126 / 183-\mathrm{kDa}$ gene of $\mathrm{Ob}$ that lead to induction of the hypersensitive response (HR). Hatched region in the genomic map represents the portion of the tobacco mosaic virus (TMV) replicase (amino acids 692 through 1116) that is required for induction of the $N$ gene-mediated HR. At the bottom is an expanded view of this region of the $\mathrm{Ob}$ replicase, indicating the positions of the mutations in $\mathrm{Ob}$ that result in HR. Shaded bars represent the nucleoside triphosphate binding domain and helicase consensus motifs. Asterisk denotes the amber termination codon in the $126 / 183-\mathrm{kDa}$ protein. 
mutation responsible for the ObNL-1 phenotype mapped to position 3334 and affected amino acid 1089, resulting in a change of proline to leucine (Padgett and Beachy 1993). Sitedirected mutagenesis was performed on the full-length cloned cDNA, pOb, as described previously (Padgett and Beachy 1993) to introduce the changes at nucleotide 3273 (ObNL-2) or nucleotide 3333 (ObNL-3). Inoculation of transcripts from the resulting constructs, pObNL-2.1 and pObNL-3.1, to NN tobacco plants confirmed that these mutations were responsible for the necrotic phenotypes of the mutants. When inoculated to leaves of Xanthi nn plants, each of the mutant viruses produced systemic infection similar to that caused by wildtype $\mathrm{Ob}$, indicating that the mutations did not result in significant losses of pathogenicity (data not shown).

An attempt was made to obtain suppressor mutants of ObNL-1 and ObNL-3 that would restore the ability to overcome the $N$ gene-mediated HR. To discriminate between true revertants and possible contamination by wild-type $\mathrm{Ob}$, a single nucleotide change of $\mathrm{G}$ to $\mathrm{T}$ was introduced at residue 6119 within the CP genes of pObNL-1 and pObNL-3. The change was translationally silent but created an additional HpaI restriction site that could be used to identify progeny derived from these clones. Virus derived from each clone was inoculated to leaves of six Xanthi NN plants that were maintained at $24^{\circ} \mathrm{C}$ for several weeks. One systemic variant of each mutant virus was obtained. Cloned cDNAs containing the relevant sequences from the variants were isolated and sequenced, and, in each case, the $N$ gene-inducing mutation had reverted to the wild-type sequence (data not shown).

A third mutant of $\mathrm{Ob}$ that elicited the HR on Xanthi NN plants was derived from an $\mathrm{Ob}$ isolate sequenced by Ikeda et al. (1993). However, unlike the wild-type Ob used in our laboratory, this strain was reported to cause HR on inoculated leaves of NN tobacco plants prior to systemic invasion of the plant. The sequence of this isolate differs from pOb by $6 \mathrm{nt}, 2$ of which lead to amino acid changes. Fragments of a cloned cDNA representing most of the genome of this variant, pOb10, were exchanged into pOb and the nucleotide difference responsible for its phenotype was determined to be nucleotide 2687. This led to the predicted change of lysine at amino acid position 873 to asparagine (Fig. 3). The Ob construct containing this change was named pObYW-2-2. This mutation, as well as those of ObNL-1, ObNL-2, and ObNL-3, lies within the region that, in the TMV replicase, is necessary for induction of HR (Fig. 2A).

\section{Thermosensitivity of the $N$ gene-mediated HR induced by different tobamoviruses.}

It has long been known that TMV overcomes the effects of the $N$ gene at temperatures above $28^{\circ} \mathrm{C}$ (Samuel 1931). To determine whether the HR elicited by the ObNL mutants would be similarly temperature sensitive, $\mathrm{NN}$ tobacco plants were inoculated with virus of ObNL-1.1 (Padgett and Beachy 1993), ObNL-2.1, ObNL-3.1, ObYW-2-2, wild-type Ob, or TMV. The infected plants were maintained in growth chambers at constant temperatures ranging from 18 to $28^{\circ} \mathrm{C}$ at 2degree increments and observed over a 2-week period for necrotic as well as systemic symptoms. On plants in which the infection appeared to be localized to the inoculated leaf, the absence of systemic spread was confirmed by infectivity assays of extracts from upper leaves.
As in previous reports (Samuel 1931; Takahashi 1975; Gulyas and Farkas 1978; Weststeijn 1981), TMV was localized to the inoculated leaf at $26^{\circ} \mathrm{C}$, but caused systemic symptoms above that temperature. ObNL-1.1 and ObNL-3.1 induced HR and were localized at $24^{\circ} \mathrm{C}$ and below, whereas ObNL-2.1 and ObYW-2-2 caused necrosis and were localized to the inoculated leaf at $20^{\circ} \mathrm{C}$ and below. At 1 to $2^{\circ} \mathrm{C}$ above the temperatures of effective virus localization indicated in Table 1, plants frequently showed necrosis on the inoculated leaves with either systemic mosaic or necrotic flecking in the upper, systemically infected leaves, often accompanied by stunting of the plant. Wild-type $\mathrm{Ob}$ systemically infected NN tobacco at $18^{\circ} \mathrm{C}$, although necrotic symptoms on the inoculated leaves were occasionally observed at this temperature. Studies were not performed at temperatures lower than $18^{\circ} \mathrm{C}$. The results presented here suggest that temperature sensitivity of the $N$ gene-mediated HR is influenced by the virus, occurring either at the point of recognition of the virus by the plant, or at some other step in the response pathway where a product of infection, possibly the $126 / 183-\mathrm{kDa}$ protein, interacts with the host defense mechanism.

\section{DISCUSSION}

The $N$ gene-mediated HR has long served as a model system for hypersensitive disease resistance in plants. Though much has been learned about the biochemistry and physiology of the response (Fritig et al. 1987), little is known regarding the nature of the viral elicitor and its recognition by the plant. In this work, we characterized the viral elicitor of the $N$ genemediated HR with Ob/TMV hybrid genomes and mutants of $\mathrm{Ob}$ that elicit the necrotic response. These mutants also provided insight into the thermosensitive behavior of the $N$ genemediated HR.

Our studies demonstrated that amino acids 692 to 1116 of the replicase protein of TMV are responsible for activation of the $N$ gene-mediated HR. Likewise, mutations in the $\mathrm{Ob}$ genome that led to induction of the $N$ gene response caused changes within the same region of the protein. This portion of the replicase contains sequences that are homologous to the helicases within a superfamily of replicative proteins that are characterized by well-defined amino acid consensus motifs that are required for nucleoside triphosphate binding and hydrolysis as well as for RNA unwinding activity (Gorbalenya and Koonin 1993; Fernandez et al. 1995). It is not known whether induction of the HR is mediated by recognition of specific structural features of the protein, or by its enzymatic

Table 1. Temperature sensitivity of $N$ against TMV (tobacco mosaic virus), $\mathrm{Ob}$, and ObNL mutants

\begin{tabular}{lcccccc}
\hline & \multicolumn{5}{c}{ HR elicitation and virus localization } \\
\cline { 2 - 7 } Virus $^{\mathrm{a}}$ & $\mathbf{1 8}^{\circ} \mathbf{C}$ & $\mathbf{2 0}^{\circ} \mathbf{C}$ & $\mathbf{2 2}^{\circ} \mathbf{C}$ & $\mathbf{2 4}^{\circ} \mathbf{C}$ & $\mathbf{2 6}^{\circ} \mathbf{C}$ & $\mathbf{2 8}^{\circ} \mathbf{C}$ \\
\hline TMV & $+^{\mathrm{b}}$ & + & + & + & + & $-^{\mathrm{b}}$ \\
ObNL-1.1 & + & + & + & + & - & - \\
ObNL-3.1 & + & + & + & + & - & - \\
ObNL-2.1 & + & + & - & - & - & - \\
ObYW-2-2 & + & + & - & - & - & - \\
Ob & - & - & - & - & - & - \\
\hline
\end{tabular}

${ }^{a}$ Viruses were tested for induction of the hypersensitive response (HR) and localization to inoculated leaves of tobacco cv. Xanthi NN.

${ }^{\mathrm{b}}(+)$, HR accompanied by virus localizations; (-), systemic virus spread. 
activity. If the latter is the case, however, changes in the activity of the $\mathrm{Ob}$ replicase that lead to induction of the HR (i.e., by the ObNL mutants) are apparently not severe, as those viruses retained the pathogenicity of $\mathrm{Ob}$ on susceptible plants.

Although a fragment of the $126-\mathrm{kDa}$ protein induced HR, it is uncertain whether the protein is the sole elicitor of the defense response or whether additional viral factors are required. In the case of the HR mediated by the $N^{\prime}$ gene in response to the TMV CP, the expression of elicitor-active CP molecules in transgenic plants or callus cultures was sufficient to activate the HR (Culver et al. 1991; Pfitzner and Pfitzner 1992). In contrast, when the tobacco cv. Xanthi nc ( $N N$ genotype) was transformed with the gene encoding the entire TMV $183-\mathrm{kDa}$ protein under the control of a strong constitutive promoter, the transgenic plants were reported to show no significant differences from nontransformed control plants (Donson et al. 1993). The apparent lack of spontaneous necrosis in these plants may relate to possible failure of the replicase protein to accumulate to a threshold level for activation of $\mathrm{HR}$, or to the requirement of more than one viral component for induction of hypersensitivity. It has been shown that intact cell-to-cell connections are required for the necrotic reaction against TMV in N. tabacum cv. Xanthi nc plants (Gulyas and Farkas 1978) and that hypersensitivity to TMV infection does not occur in protoplasts (Otsuki et al. 1972) while it does in cultured calli (Beachy and Murakishi 1971). These facts suggest the possibility that the TMV movement protein, which alters size exclusion limits of plasmodesmata (Wolf et al. 1989), may be involved in intracellular signaling pathways that lead to necrosis (Deom et al. 1991).

We used the necrotic mutants of $\mathrm{Ob}$ to analyze the wellknown temperature sensitivity of the $N$ gene-mediated HR. Previously, it was shown that high temperatures inhibit an early event in the initiation of necrosis induced by TMV (Samuel 1931; Takahashi 1975; Gulyas and Farkas 1978; Weststeijn 1981). However, those studies could not identify the step(s) in the response pathway that are thermosensitive. We found that the temperature at which the HR is inactivated differed among TMV and the Ob mutants, suggesting that the temperature sensitivity reflects a property of the virus and not the defense response mechanism, per se. We propose that elevated temperatures may weaken the interaction between the viral elicitor and the host surveillance mechanism that leads to activation of the HR. The nature of this interaction is uncertain. A second hypothesis states that differences between $\mathrm{Ob}$ and the ObNL mutants in p126/183 result in differences in activity of the replicase. At the present time we favor the former hypothesis since preliminary studies of replication of these viruses in tobacco protoplasts did not reveal obvious differences between the replication of $\mathrm{Ob}$ and the ObNL mutants (H. Padgett, Y. Watanabe, and R. Beachy, unpublished).

$\mathrm{Ob}$ is unique among tobamoviruses in its ability to overcome the $N$ gene-mediated HR (Tobias et al. 1982; Csillery et al. 1983), presumably due to either passive or active mechanisms. In a passive mode, the virus would either mask, not produce, or otherwise limit the availability of the determinant that is recognized by the host. It has been suggested that the U1 strain of TMV overcomes the HR mediated by the $N^{\prime}$ gene in a passive way (Culver et al. 1991; Taraporewala and Culver 1996). In the case of Ob, a similar conclusion was reached when $N$ gene tobacco plants were inoculated with mixtures of
Ob and TMV (Sanfaçon et al. 1993). Since TMV was localized to the inoculated leaves in the presence of $\mathrm{Ob}$ in those experiments, it was evident that $\mathrm{Ob}$ did not confer upon TMV the ability to overcome resistance.

The $\mathrm{Ob}$ isolate used in the experiments by Sanfaçon et al. (1993) was able to infect NN tobacco systemically, and to induce local necrosis on inoculated leaves. These results suggested that the isolate of $\mathrm{Ob}$ used by these workers may have had some similarity to the $\mathrm{Ob}$ mutants used in the present study that were diminished in capacity to overcome resistance. Although we have not tested our Ob mutants by coinoculation with TMV, in preliminary studies we found that wild-type $\mathrm{Ob}$ can promote the systemic spread of TMV in coinoculated NN tobacco plants (H. Padgett and R. Beachy, unpublished). These results suggest that the $\mathrm{Ob}$ used in our studies is different from the Ob used by Sanfaçon et al. (1993) and further study may clarify the mechanisms through which $\mathrm{Ob}$ overcomes the $N$ gene-mediated HR.

In summary, we identified the minimal sequences of the $126 / 183-\mathrm{kDa}$ protein of HR-eliciting tobamoviruses that are required for induction of the $N$ gene-mediated HR. We also demonstrated that the temperature sensitivity of the HR is influenced by the viral pathogen, and likely represents a step at which p126/183 interacts with the defense response mechanisms. Identification of the viral components responsible for eliciting the $N$ gene-mediated HR, and analysis of how recognition occurs, will aid in understanding the biochemical and molecular mechanisms of the perception and subsequent responses to pathogen attack.

\section{MATERIALS AND METHODS}

\section{Construction of TMV/Ob hybrid virus genomes.}

Numbering of TMV and $\mathrm{Ob}$ sequences is according to Goelet et al. (1982) and Padgett and Beachy (1993), respectively. pT/O-MC3' was constructed by removing the TMV CP and 3' UTR sequences from pT/O-M (Padgett and Beachy 1993) by digestion with KpnI followed by treatment with T4 DNA polymerase in the presence of deoxynucleoside triphosphates (dNTPs), and subsequent digestion by PstI. These sequences were replaced by a DNA fragment encoding the $\mathrm{Ob}$ $\mathrm{CP}$ and 3' UTR that was prepared by digestion of pOb with BstEII followed by treatment with the Klenow fragment of Escherichia coli DNA polymerase I in the presence of dNTPs, followed by cleavage with PstI.

The plasmid pO/T-MC3' was constructed by first isolating a fragment from pU3/12-4 (Holt and Beachy 1991) that extended from the NcoI site (nucleotide 5459) to the KpnI site (immediately adjacent to the $3^{\prime}$ end of the viral genomic sequence) that had been blunted in a reaction with T4 DNA polymerase plus dNTPs. This fragment was inserted into the vector $\mathrm{pO} / \mathrm{T}-\mathrm{M}$ after digestion with BstEII and blunting with Klenow fragment plus dNTPs, followed by digestion with NcoI. pO/T-M was assembled by isolating the Klenow-treated $N d e$ I to AflII fragment that represents the TMV MP open reading frame (ORF) in clone pT3NA (Deom et al. 1994) and ligating it into the Ecl136II ( $S a c$ I isoschizomer) site of pOb $\Delta \mathrm{M}-S a c \mathrm{I}$. pOb $\Delta \mathrm{M}-S a c \mathrm{I}$ was made by first disrupting the unique $S a c$ I site present in the pUC19 polylinker sequences of pOb by linearizing pOb with $S a c I$, then treating with Klenow fragment plus dNTPs with subsequent ligation to re-close the 
vector. Next, the first 238 bases of the Ob MP sequence were deleted and replaced with a SacI site by standard PCR mutagenesis techniques.

\section{Identification and truncation of replicase fragments that cause $\mathrm{HR}$.}

Plasmids pO/T-R2, pO/T-R3, pO/T-R6, and pO/T-R7 were constructed by inserting DNA sequences that encode segments of the TMV 126/183-kDa replicase gene into pOb $\Delta \mathrm{M}-\mathrm{SacI}$. The TMV replicase gene fragments used to make these clones were obtained from the clone pU3/12-ROPL, a derivative of pU3/12-4 from which the MP and CP gene sequences had been deleted and replaced with a polycloning site (Heinlein et al. 1995). pU3/12-ROPL was digested with SmaI (TMV nucleotide 258), StuI (nucleotide 1677), ScaI (nucleotide 3315), or HaeII (nucleotide 3471), all followed by blunting with T4 DNA polymerase to generate the $5^{\prime}$ termini of the inserts, as indicated, for the construction of $\mathrm{pO} / \mathrm{T}-\mathrm{R} 2, \mathrm{pO} / \mathrm{T}-\mathrm{R} 3, \mathrm{pO} / \mathrm{T}-$ $\mathrm{R} 6$, and $\mathrm{pO} / \mathrm{T}-\mathrm{R} 7$ respectively. The $3^{\prime}$ termini of the inserts were co-terminal with the $183-\mathrm{kDa}$ TMV replicase gene and were generated by digestion with PstI, which cuts immediately downstream of the replicase ORF. These fragments were ligated separately into $\mathrm{pOb} \Delta \mathrm{M}-\mathrm{SacI}$ that had been digested with Ecl136II and PstI.

Plasmids $\mathrm{pO} / \mathrm{T}-1.7, \mathrm{pO} / \mathrm{T}-2.1, \mathrm{pO} / \mathrm{T}-2.5, \mathrm{pO} / \mathrm{T}-2.8$, and $\mathrm{pO} / \mathrm{T}-3.1$ were generated by the PCR method described by Barnes (1994) to amplify fragments of the TMV replicase that began at the nucleotide positions of the viral sequences that are denoted (in kilobases) in the names of the clones, and extend to the 3' terminus of the TMV $126-\mathrm{kDa}$ gene. The forward primers used for amplification annealed to nucleotides 1689 through 1706, 2142 through 2159, 2470 through 2488, 2796 through 2816, and 3063 through 3092, respectively, of the TMV genomic sequence. These PCR reactions were performed with the same reverse primer that anneals to nucleotides 3399 through 3418 of the TMV genome and is flanked by a PstI site. This primer was designed to convert the UAG (amber) codon at the $\mathrm{C}$ terminus of the $126-\mathrm{kDa}$ protein to a UAA stop codon. The PCR products were treated with Klenow fragment plus dNTPs followed by digestion with PstI and inserted into pOb $\Delta \mathrm{M}-\mathrm{SacI}$ that had been digested with Ecl136II and PstI.

The C-terminal deletions, pO/TCT-3.2, pO/TCT-2.9, and pO/TCT-2.6, were constructed by first synthesizing PCR fragments derived from the TMV replicase with the same forward primer (nucleotides 1689 through 1706) for each reaction paired with individual primers that annealed to either 3225 through 3245,2862 through 2891, or 2559 through 2579, respectively. After treatment with Klenow fragment plus dNTPs followed by PstI digestion, the PCR products were ligated into $\mathrm{pOb} \Delta \mathrm{M}-\mathrm{SacI}$ that had been digested with Ecl136II and PstI.

The construction of both $\mathrm{pO} / \mathrm{O}-1.7$ and $\mathrm{pO} / \mathrm{NL} 1-1.7$ was performed essentially as described for $\mathrm{pO} / \mathrm{T}-1.7$. The forward primer that was used to amplify the TMV fragment in $\mathrm{pO} / \mathrm{T}$ 1.7 contained sufficient homology to pOb to be used for PCR with $\mathrm{pOb}$ and pObNL-1 templates. It led to changes in 2 amino acids near the amino termini of the polypeptides encoded by the amplified replicase fragments. The reverse PCR primer for these reactions annealed to nucleotides 3396 through 3415 of pOb, and converted the amber codon at the $3^{\prime}$ end of the 126-kDa replicase ORF to a stop codon, which was followed by a flanking PstI site. The products of these PCR reactions were treated with Klenow fragment in the presence of dNTPs followed by digestion with PstI, and inserted into pOb $\Delta \mathrm{M}-S a c \mathrm{I}$ that had been digested with Ecl136II and PstI.

Generation and analysis of necrotic lesion mutants of $\mathrm{Ob}$.

Hydroxylamine mutagenesis, screening for necrotic lesion mutants, and the subsequent steps of virus purification and viral RNA preparation were performed as previously described (Padgett and Beachy 1993) except that infected plants were maintained at $20^{\circ} \mathrm{C}$ during the process of screening and analysis of the mutant viruses.

The genomes of ObNL-2 and ObNL-3 were cloned in segments that represented the entire viral sequences except for $445 \mathrm{nt}$ at their $5^{\prime}$ termini and $10 \mathrm{nt}$ at their $3^{\prime}$ termini, respectively. First-strand cDNAs of ObNL-2 and ObNL-3 were synthesized with the primer $\mathrm{Ob} 1^{\mathrm{ST}}$, which anneals to the $3^{\prime}$ terminus of the viral RNA as previously described (Padgett and Beachy 1993). The resulting cDNA from each virus was used as template for three separate PCR reactions, A, B, and $\mathrm{C}$, of 15 cycles each, to generate three contiguous fragments that were used to replace the analogous wild-type $\mathrm{Ob}$ sequences in $\mathrm{pOb}$.

The primer pairs that were used to generate these PCR products consisted of forward and reverse primers that flanked the unique SphI (nucleotide 449) and XbaI (nucleotide 3255) sites in pOb for reaction $\mathrm{A}$, the $X b a \mathrm{I}$ and PstI (nucleotide 5170) sites for reaction $\mathrm{B}$, and the PstI and XmaI (nucleotide 6491) sites for reaction $C$, respectively. These unique restriction sites were used to insert the individual fragments into $\mathrm{pOb}$ after digestion with the same enzymes. Two sets of $\mathrm{Ob} / \mathrm{ObNL}$ mutant hybrid clones, pObNL-2A, pObNL-2B, and pObNL-2C of one, and pObNL-3A, pObNL-3B, and pObNL$3 \mathrm{C}$ of the other, were constructed in this way. pObNL-2D and pObNL-3D were constructed by replacing the sequence between $X b a \mathrm{I}$ and $M l u \mathrm{I}$ (nucleotides 3255 through 4081) of pOb with fragment $\mathrm{D}$, an internal segment from fragment $\mathrm{B}$ of ObNL-2 and ObNL-3, respectively.

\section{Plant inoculation.}

Infectious viral transcripts were synthesized in vitro as described by Padgett and Beachy (1993). Leaves of the appropriate tobacco hosts were mechanically inoculated either with transcripts or with virus, as indicated. Virions of TMV were inoculated at a concentration of $0.1 \mu \mathrm{g} / \mathrm{ml}$. Inoculations with $\mathrm{Ob}$ and the $\mathrm{ObNL}$ mutants were performed at 0.3 to $0.5 \mu \mathrm{g} / \mathrm{ml}$. Inoculated plants were maintained at constant temperature of $24^{\circ} \mathrm{C}$ unless otherwise indicated.

\section{ACKNOWLEDGMENTS}

We would like to thank Sally Jo Leitner for maintenance of plant material. Support was provided by The Scripps Research Institute.

\section{LITERATURE CITED}

Barnes, W. M. 1994. PCR amplification of up to 35-kb DNA with high fidelity and high yield from lambda bacteriophage templates. Proc. Natl. Acad. Sci. USA 91:2216-2220.

Beachy, R. N., and Murakishi, H. H. 1971. Local lesion formation in tobacco tissue culture. Phytopathology 61:877-878. 
Csillery, G., Tobias, I., and Rusko, J. 1983. A new pepper strain of tomato mosaic virus. Acta Phytopathol. Acad. Sci. Hung. 18:195-200.

Culver, J., Lindbeck, A., and Dawson, W. O. 1991. Virus-host interactions: Induction of chlorotic and necrotic responses in plants by tobamoviruses. Annu. Rev. Phytopathol. 29:193-217.

Deom, C. M., He, X. Z., Beachy, R. N., and Weissinger, A. K. 1994. Influence of heterologous tobamovirus movement protein and chimeric-movement protein genes on cell-to-cell and long-distance movement. Virology 205:198-209.

Deom, C. M., Oliver, M. J., and Beachy, R. N. 1987. The 30-kilodalton gene product of tobacco mosaic virus potentiates virus movement. Science 237:389-394.

Deom, C. M., Wolf, S., Holt, C. A., Lucas, W. J., and Beachy, R. N. 1991. Altered function of the tobacco mosaic virus movement protein in a hypersensitive host. Virology 180:251-256.

Donson, J., Kearney, C. M., Turpen, T. H., Khan, I. A., Kurath, G., Turpen, A. M., Jones, G. E., Dawson, W. O., and Lewandowski, D. J. 1993. Broad resistance to tobamoviruses is mediated by a modified tobacco mosaic virus replicase transgene. Mol. Plant-Microbe Interact. 6:635-642.

Dunigan, D. D., and Madlener, J. C. 1995. Serine-threonine protein phosphatase is required for tobacco mosaic virus-mediated programmed cell death. Virology 207:460-466.

Fernandez, A., Lain, S., and Garcia, J. A. 1995. RNA helicase activity of the plum pox potyvirus CI protein expressed in Escherichia coli. Mapping of an RNA binding domain. Nucleic Acids Res. 23:1327-1332.

Fritig, B., Kauffmann, B., Dumas, P., Geoffroy, M., Kopp, M., and Legrand, M. 1987. Mechanism of the hypersensitivity reaction of plants. Pages 92-108 in: Plant Resistance to Viruses. D. Evered and S. Harnett, eds. Wiley, Chichester, UK.

Goelet, G. P., Lomonossoff, G. P., Butler, P. J. G., Akam, M. E., Gait, M. J., and Karn, J. 1982. Nucleotide sequence of tobacco mosaic virus RNA. Proc. Natl. Acad. Sci. USA 79:5818-5822.

Gorbalenya, A. E., and Koonin, E. V. 1993. Helicases: Amino acid sequence comparisons and structure-function relationships. Curr. Opin. Struct. Biol. 3:419-429.

Gulyas, A., and Farkas, G. L. 1978. Is cell-to-cell contact necessary for the expression of the $\mathrm{N}$-gene in Nicotiana tabacum cv. Xanthi nc. plants infected by TMV? Phytopathol. Z. 91:182-187.

Heinlein, M., Epel, B. L., Padgett, H. S., and Beachy, R. N. 1995. Interaction of tobamovirus movement proteins with the plant cytoskeleton. Science 270:1983-1985.

Holt, C. A., and Beachy, R. N. 1991. In vivo complementation of infectious transcripts from mutant tobacco mosaic virus cDNAs in transgenic plants. Virology 181:109-117.

Ikeda, R., Watanabe, E., Watanabe, Y., and Okada, Y. 1993. Nucleotide sequence of tobamovirus $\mathrm{Ob}$ which can spread systemically in $N$ gene tobacco. J. Gen. Virol. 74:1939-1944.

Jones, J. D. G. 1996. Plant disease resistance genes: Structure, function and evolution. Curr. Opin. Biotechnol. 7:155-160.

Keen, N. T. 1990. Gene-for-gene complementarity in plant-pathogen interactions. Annu. Rev. Genet. 24:447-463.

Keen, N. T. 1992. The molecular biology of disease resistance. Plant Mol. Biol. 19:109-122.

Otsuki, Y., Shimomura, T., and Takebe, I. 1972. Tobacco mosaic virus multiplication and expression of the $N$ gene in necrotic responding tobacco varieties. Virology 50:45-50.

Padgett, H. S., and Beachy, R. N. 1993. Analysis of a tobacco mosaic virus strain capable of overcoming $N$ gene-mediated resistance. Plant Cell 5:577-586

Pelham, H. R. B. 1978. Leaky UAG termination codon in tobacco mosaic virus RNA. Nature 272:469-471.

Pfitzner, U. M., and Pfitzner, A. J. P. 1992. Expression of a viral avirulence gene in transgenic plants is sufficient to induce the hypersensitive defense reaction. Mol. Plant-Microbe Interact. 5:318-321.

Samuel, G. 1931. Some experiments on inoculating methods with plant viruses, and on local lesions. Ann. Appl. Biol. 18:494-507.

Sanfaçon, H., Cohen, J. V., Elder, M., Rochon, D. M., and French, C. J. 1993. Characterization of Solanum dulcamara yellow fleck-Ob: A tobamovirus that overcomes the $N$ resistance gene. Phytopathology 83: 400-404.

Takahashi, T. 1975. Studies on viral pathogenesis in plant hosts VIII. Systemic virus invasion and localization of infection on 'Samsun NN' tobacco plants resulting from tobacco mosaic virus infection. Phytopathol. Z. 84:75-87.

Taraporewala, Z. F., and Culver, J. N. 1996. Identification of an elicitor active site within the three-dimensional structure of the tobacco mosaic tobamovirus coat protein. Plant Cell 8:169-178.

Tobias, I., Rast, B., and Maat, D. Z. 1982. Tobamoviruses of pepper, eggplant, and tobacco: Comparative host reactions and serological relationships. Neth. J. Plant Pathol. 88:257-268.

Weststeijn, E. A. 1981. Lesion growth and virus localization in leaves of Nicotiana tabacum cv. Xanthi nc. after inoculation with tobacco mosaic virus and incubation alternately at $22 \mathrm{C}$ and $32 \mathrm{C}$. Physiol. Plant Pathol. 18:357-368.

Whitham, S., Dinesh-Kumar, S. P., Choi, D., Hehl, R., Corr, C., and Baker, B. 1994. The product of the tobacco mosaic virus resistance gene $N$ : Similarity to Toll and the Interleukin-1 receptor. Cell 78: 1101-1115.

Wolf, S., Deom, C. M., Beachy, R. N., and Lucas, W. J. 1989. Movement protein of tobacco mosaic virus modifies plasmodesmatal size exclusion limit. Science 246:377-379. 